\title{
Trade-off or coordination? Correlations between ballochorous and myrmecochorous phases of diplochory
}

\author{
Si-Chong Chen ${ }^{1,2}$ (D) | Amir H. Pahlevani ${ }^{3}$ | Lenka Malíková2,4 ${ }^{2,4}$ Ricarda Riina ${ }^{5}$ | \\ Fiona J. Thomson ${ }^{6}$ | Itamar Giladi ${ }^{2}$
}

${ }^{1}$ Royal Botanic Gardens, Kew, Wakehurst Place, UK; ${ }^{2}$ Mitrani Department of Desert Ecology, Swiss Institute for Dryland Environmental and Energy Research, Jacob Blaustein Institutes for Desert Research, Ben-Gurion University of the Negev, Midreshet Ben-Gurion, Israel; ${ }^{3}$ Department of Botany, Iranian Research Institute of Plant Protection, Agricultural Research, Education and Extension Organization, Tehran, Iran; ${ }^{4}$ Department of Biological Disciplines, Faculty of Agriculture, University of South Bohemia, České Budějovice, Czech Republic; ${ }^{5}$ Real Jardín Botánico, RJB-CSIC, Madrid, Spain and ${ }^{6}$ Landcare Research, Lincoln, New Zealand

\section{Correspondence \\ Si-Chong Chen \\ Email: s.chen@kew.org}

Funding information Israel Science Foundation, Grant/Award Number: 834/15; Blaustein Center for

Scientific Cooperation

Handling Editor: Daniel García

\section{Abstract}

1. The combination of two dispersal syndromes (diplochory) brings additional benefits to seeds, yet the relative costs and benefits of the two phases are poorly understood. Our goal is to provide the first quantification to test the long-standing assumption that there are trade-offs between the two phases in ballistic-ant diplochory.

2. Dispersal investment data were empirically measured for 91 Euphorbiaceae species across different regions of the world. Dispersal distance data of ballochory (seed dispersal by explosion), myrmecochory (seed dispersal by ants) and diplochory was collated from the literature for 210 records (148 species from 44 families). The data were analysed using Model II regression, Kolmogorov-Smirnov test and $t$ test, complemented by phylogenetic comparative approaches.

3. Across diaspores of diplochorous species, the relative investment in myrmecochory increased more than that in ballochory. Fruit coat mass and elaiosome mass covaried in an allometric manner, regardless of seed mass. Diplochorous diaspores were significantly heavier than diaspores dispersed solely by ballochory. Dispersal distances of the two diplochorous phases were independent and comparable to that of sole ballochory or sole myrmecochory.

4. Our results do not support a trade-off, but a coordinated dispersal strategy between the two diplochorous phases. Large diaspores may evolve diplochory to overcome dispersal difficulties in term of dispersal distance. As the most comprehensive study of ballistic-ant diplochory, our findings advance the understanding of the relative importance of the two phases in diplochory.

\section{KEYWORDS}

dispersal distance, dispersal investment, Euphorbia, Mercurialis annua, seed dispersal, seed mass 


\section{1 | INTRODUCTION}

Seed dispersal is a complex process where seeds can be transported in one or more sequential phases, potentially involving several dispersal agents (Howe \& Smallwood, 1982; Vander Wall \& Longland, 2004). Many species are associated with a single-phase dispersal syndrome (monochory), where species have structures adapted for a particular dispersal mechanism, such as a wing for wind dispersal. Diplochory refers to the case where species disperse their seeds in two separate phases, usually associated with different dispersal structures and presenting different types of adaptations to different dispersal agents (Vander Wall \& Longland, 2004). In the two sequential phases of diplochory, phase I dispersal scatters seeds away from parent plants (sometimes in lower density), while in phase II dispersal seeds are transported a further distance or to more suitable habitats for recruitment (Schupp, Jordano, \& Gómez, 2010; Vander Wall \& Longland, 2004). Compared to any single-phase dispersal syndrome, diplochory is thought to provide greater seed dispersal effectiveness (Camargo, Martins, Feitosa, \& Christianini, 2016; Culot, Huynen, \& Heymann, 2015; Schupp et al., 2010), reduce seed predation (Beattie \& Lyons, 1975) and result in a double seed bank (Bülow-Olsen, 1984).

Several types of diplochory have been identified (Vander Wall \& Longland, 2004), with one of the most common types being where seeds are first dispersed by explosive ejection (hereafter, ballochory) and then further dispersed by ants (hereafter, myrmecochory; see Table S1 for a synthesis of species). For the ballochorous phase, the dehydrated valves of the fruit coat mechanically propel seeds in various directions (Berg, 1966; Hayashi, Feilich, \& Ellerby, 2009; Lisci \& Pacini, 1997). For the myrmecochorous phase, the lipid-rich elaiosomes sensu lato function as a nutritional reward to facilitate seed removal by ants (Hughes \& Westoby, 1992; Mark \& Olesen, 1996). The relative importance of the two phases varies among species, and diplochory may favour one phase over the other (Ohkawara \& Higashi, 1994; Zhu, Wang, Zhang, \& Liu, 2018). However, we currently lack an empirical quantification of the cross-species relationships of dispersal attributes between the two phases, nor do we have comparisons of dispersal attributes between diplochory and the corresponding monochory (i.e. sole ballochory or sole myrmecochory). We aim to address these knowledge gaps in dispersal investment and dispersal distance.

Our first aim (Aim 1) is to quantify the relationships between seed mass, biomass investment in ballochorous structures (i.e. fruit coat) and biomass investment in myrmecochorous structures (i.e. elaiosome) in diplochorous species. It has long been proposed that diplochorous plants display a trade-off strategy of biomass allocation between dispersal structures (Narbona, Ortiz, \& Arista, 2016; Stamp $\&$ Lucas, 1983). However, investment in fruit coat is rarely measured, limiting the evaluation of relative investments between the two phases. We expect that greater investment in dispersal structures of one phase may result in lower availability of resources to invest in dispersal structures of the other phase. Seed mass also affects dispersal structure mass (Chen \& Giladi, 2018), but it is unknown if diplochorous species invest a higher proportion of biomass in the ballochorous phase or in the myrmecochorous phase with increasing diaspore size. Edwards, Dunlop, and Rodgerson (2006) found a positive allometry between seed mass and elaiosome mass across 207 myrmecochorous species, suggesting that elaiosome mass increases proportionally more than the increase of seed mass. It is unknown whether such allometry persists in diplochory when myrmecochory is the secondary dispersal phase. Although seed mass also influences ballochory (Lisci \& Pacini, 1997), there lacks a quantification so far that relates seed mass to relative investment in fruit coat. Thus, the questions have not been answered yet on whether plants require proportionally more investment in fruit coat to eject larger seeds, and how the scaling relationships between seed and dispersal structures differ between the two phases of diplochory.

Our second aim (Aim 2) is to test whether diplochorous species invest a similar amount of biomass in each dispersal structure compared to the investment in corresponding structures of species with either sole ballochory or sole myrmecochory. Since both ballochory and myrmecochory are assisted by dispersal structures (Lisci \& Pacini, 1997), the combination of these two dispersal structures is materially costly compared to sole ballochory or sole myrmecochory (Bülow-Olsen, 1984). For example, diplochorous Viola species (Violaceae) usually have woody and thickened capsule valves that can violently propel seeds, but their elaiosomes tend to be smaller than their congeneric species that are solely dispersed by ants (Beattie \& Lyons, 1975). Similar patterns are also found in Corydalis (Papaveraceae), where diplochorous species have smaller elaiosomes than their congeneric species with sole myrmecochory (Nakanishi, 1994).

Our third aim (Aim 3) is to quantify the relationship between ballochory distance and myrmecochory distance in diplochorous species, and test whether dispersal distances would influence each other. We expect that there is a trade-off between seed dispersal distances of the two phases, because optimization for one phase will constrain the optimization for the other phase. It is known that the presence of an elaiosome alters the mass and the streamlining of a diaspore and consequently impedes ballistic flight (Beattie \& Lyons, 1975). Experimental evidence has also shown in several congeneric pairs of diplochorous taxa that species with a longer ballochory distance exhibits a shorter myrmecochory distance (Culver \& Beattie, 1978; Ohkawara \& Higashi, 1994; Zhu et al., 2018). However, these studies are only based on comparisons of paired species, and exceptions showing a contrary pattern also exist (Aranda-Rickert \& Fracchia, 2010). A synthesis across multiple species is needed in this context.

Our final aim (Aim 4) is to test whether the distribution of dispersal distances achieved by each phase in diplochory is similar with that achieved by sole ballochory or by sole myrmecochory, respectively. Under the hypothesis that the optimization for dispersal distance in one phase is constrained by the other, we expect that diplochorous plants disperse their seeds to a reduced distance in each phase. For example, in a comparison of two Euphorbia species (Euphorbiaceae), the species with tiny and easily detachable elaiosomes eject seeds 
further but have substantially shorter myrmecochory distance than does the congeneric species with larger elaiosomes (Narbona, Arista, \& Ortiz, 2005).

In this study, we examine the relationships of dispersal distances and the relationships of dispersal investments between the two phases of diplochory. We also explore the costs and benefits of dispersal in diplochory to those in sole ballochory or in sole myrmecochory, attempting to explain the circumstances under which some species may evolve the two-phase seed dispersal syndrome. We seek to provide new insights to several long-standing assumptions in the evolution of ballistic-ant diplochory.

\section{2 | MATERIALS AND METHODS}

\section{1 | Data collection}

A dataset of dispersal investment for Aims 1 and 2 was acquired through empirical measurements of species from the Euphorbiaceae. Dispersal investment in diplochorous structures has been scarcely reported in the literature (see the Supporting Information in Thomson, Letten, Tamme, Edwards, \& Moles, 2018). We measured dry mass of fruit coats, elaiosomes, and seeds for 90 Euphorbia species and a diplochorous species Mercurialis annua (Euphorbiaceae; hereafter included in the Euphorbia dataset) which were compiled from botanical gardens, natural areas and herbaria of different regions (Table S2). As one species could be sampled at several locations or herbaria (i.e. several entries), we used the mean average values for each species. We acknowledge that phenotypes of cultivated plants could differ with those of wild plants (Ensslin \& Godefroid, 2019). However, only four entries of data were directly sampled in botanical gardens (Table S2), and there was not a priori reason to expect a systematic bias in plants sampled from different sources. The genus Euphorbia is one of the major taxa exhibiting ballistic-ant diplochory (see Table S1 for a collated list of species with ballistic-ant diplochory). Their fruits are capsules harbouring a fixed number of seeds (three seeds in Euphorbia, and two seeds in M. annua). In diplochorous Euphorbia species, fruit valves launch a seed in explosive dehiscence and an appendage (caruncle) attached to the seed serves as an elaiosome. The Euphorbia species that do not bear distinguishable elaiosomes are not dispersed by myrmecochory (Baiges, Espadaler, \& Blanché, 1991). Data for M. annua were obtained at the beginning of data collection, before we finalized the design of the whole study. We hereafter included M. annua in all the analyses because this species has diplochorous diaspores in a similar form with those of Euphorbia species, and was used as the outgroup in the phylogenetic tree construction (see below and Figure S1). Overall, our dataset consisted of 68 diplochorous species (including M. annua) and 23 monochorous species (dispersed solely by ballochory; Table S2). In the dataset, seed mass data were missing for four diplochorous species and elaiosome mass data were missing for 15 diplochorous species, due to sampling difficulties (Table S2). These species were excluded in the relevant analyses, and the specific sample sizes of each analysis are presented in the sections below.
A dataset of dispersal distance for Aims 3 and 4 was acquired through a literature synthesis. We searched the ISI Web of Science for data on seed dispersal distance of ballochory and myrmecochory from papers published in English up to May 2018 and with the searching terms "seed," "dispersal," "distance," "ballistic," "ballochory," "ant" or "myrmecochory." The data were supplemented by a recent compilation of seed dispersal distance from the literature (Chen, Tamme, Thomson, \& Moles, 2019b). From each paper, we extracted mean and/or maximum seed dispersal distance data for species dispersed by ballochory and/or myrmecochory at each site. Only studies conducted on species in their natural habitats were included. Records for heteromorphic diaspores (e.g. chasmogamous seeds and cleistogamous seeds) of seven species were treated as separate data entries. We scanned the papers carefully to record whether ballochorous species were also dispersed by myrmecochory, or vice versa, and classified these species as diplochorous. We classified the other species as dispersed by either sole ballochory or sole myrmecochory. A minority of these species might also be dispersed by diplochory in other known forms (e.g. first ornithochory then myrmecochory; Passos \& Oliveira, 2002; Christianini \& Oliveira, 2010; Lima, Oliveira, \& Silveira, 2013), or even unknown forms (i.e. potential dispersal agents unreported/undescribed). We acknowledge the limitation that a small portion of species classified as monochorous might still be subject to other dispersal agents, but it is explicit that they are not dispersed by ballistic-ant diplochory. A more definitive descriptions/quantifications for some of these species are necessary in future investigations, and our dataset presents the best available compilation to this frame so far. In total, our dataset of seed dispersal distance included 88 records of ballochory distance (75 species from 15 families) and 122 records of myrmecochory distance (102 species from 37 families). Among these 210 records (148 species from 44 families), 78 records were known to exhibit diplochory (Table S3). Among the diplochorous species, 27 species were reported with both records of mean ballochory distance and mean myrmecochory distance, and 21 species were reported with both records of maximum ballochory distance and maximum myrmecochory distance. We compiled seed mass for these species from the original papers and the Seed Information Database (SID; http://data.kew.org/sid), except Viola rostrata for which seed mass was not available and was surrogated by the mean seed mass of Viola species in SID (Table S4).

\subsection{Data analysis}

To describe the relationships between the two phases of diplochory, we used Model II regression, in which a single regression line defines the bivariate relationship independently of axis switch. That is, this type of regression is appropriate when dependent and independent variables are not distinguishable (as in this study; Edwards et al., 2006; Wu, Chen, \& Wang, 2019). To quantify the scaling relationship using Model II regression, we performed reduced major axis (RMA; also called standard major axis, SMA) regression for all the analyses. RMA slopes and $95 \%$ confidence intervals $(\mathrm{Cl})$ were estimated on 
$\log _{10}$-transformed axes using the sma function in the SMATR package (Warton, Duursma, Falster, \& Taskinen, 2012). A Cl of slope below 1 indicates negative allometry, a $\mathrm{Cl}$ above 1 indicates positive allometry, and a $\mathrm{Cl}$ overlapping with 1 indicates isometry. For all the bivariate regressions, we first tested the correlation between variables. Since being non-significant, the correlation between ballochory distance and myrmecochory distance for diplochorous species was exempted from the analyses of Model II regression (Aim 3; see Results). To test for a trade-off between masses of diaspore structures across diplochorous Euphorbia species (Aim 1), we initially quantified the correlation between fruit coat mass and seed mass, and the correlation between elaiosome mass and seed mass, respectively. Then, we quantified the correlation between fruit coat mass and elaiosome mass, both without and with controlling for seed mass. To statistically control for the variation in seed mass in the relationship between fruit coat mass and elaiosome mass, we performed an RMA bivariate regression between the residuals of fruit coat mass on seed mass and the residuals of elaiosome mass on seed mass.

We complemented the analyses of Model II regression in the context of phylogeny using phylogenetic reduced major axis (pRMA) regression. As the relationships between ballochory distance and myrmecochory distance were not significant (Aim 3; see Results), we accounted for phylogeny only for the relationships between masses of diaspore components (i.e. fruit coat, elaiosome, seed) in the diplochorous Euphorbia species (Aim 1). To build a phylogeny, we created a dataset using sequences from Riina et al. (2013). We reduced the original taxon sampling to adjust it to the Euphorbia species used in this study. Euphorbia species unsampled in Riina et al. (2013), for which sequence data are now available in Genbank, were added to the new matrix along with M. annua. Seven sampled species could not be included because of lack of sequence data (i.e. E. antilibanotica, E. bifida, E. brevicornu, E. dioscoreoides, E. griffithii, E. occidentaustralica and E. sikkimensis). That is, the phylogenetic analyses were necessarily performed on a subset of the data, which could give more accurate results but lower statistical power than the cross-species analyses (Chen \& Moles, 2018). The two types of analyses show qualitatively similar results, and we present them both in the Results. Alignment and phylogenetic tree construction were performed as described in Riina et al. (2013). The resulting phylogram was rendered ultrametric (Figure S1), using penalized likelihood with smoothing parameter value 1 and the chronopl function in the APE package (Paradis, Claude, \& Strimmer, 2004). We performed pRMA regression fitted with a Pagel's $\lambda$ model, testing if the slope was equal to 1 (i.e. isometry). The analysis was conducted using the phyl. RMA function in the PHYTOOLs package (Revell, 2012). Meanwhile to a test of isometry, we calculated $95 \% \mathrm{Cl}$ of the slope fitted with a Pagel's $\lambda$ model, using the code adapted from the pgls.RMA function written by Kevin Middleton (https://rdrr.io/github/kmiddleton/ kmmisc/src/R/pgls.RMA.R).

For Aim 2, fruit coat mass and seed mass were compared between diplochorous and monochorous Euphorbia species using two-sided $t$ tests. We complemented these comparisons in the context of phylogeny, using phylogenetic analysis of variance
(pANOVA). We performed pANOVA based on 1,000 simulations using the phylANOVA function in the PHYTOOLs package (Revell, 2012).

For Aim 4, the medians of seed dispersal distance were compared between the ballochorous phase in diplochory and sole ballochory, and between the myrmecochorous phase in diplochory and sole myrmecochory, using the two-sample Mann-Whitney $U(M-W)$ test. We also performed the Kolmogorov-Smirnov (K-S) test to compare the distributions of seed dispersal distance between each diplochorous phase and the corresponding monochory. The $\mathrm{K}-\mathrm{S}$ test compares the cumulative distributions of the two datasets in shape, spread and median. It is more powerful to detect changes in the shape of the distributions but less powerful to detect a shift in the median value, compared with the $\mathrm{M}-\mathrm{W}$ test. All analyses were conducted in R (R Core Team, 2014).

\section{3 | RESULTS}

We found no evidence for a trade-off in dispersal investments between the two phases of diplochory. Across the diplochorous Euphorbia species, there was a positive relationship between masses of diaspore components (all $p<0.001$ between two components; Table 1). Fruit coat mass scaled against seed mass positively but at a lower rate than did elaiosome mass (slope $=1.26$ vs. $1.62,95 \%$ $\mathrm{Cl}=1.10-1.43$ vs. 1.32-1.99; Table 1; Figure 1a,b). Consistently, species having larger dispersal structures for ballochory also tend to have larger dispersal structures for myrmecochory (Aim 1). The allometric slope of this relationship indicated that species with large fruit coats invest proportionally more in elaiosome mass than species with small fruit coats (slope $=1.28,95 \% \mathrm{Cl}=1.04-1.59$; Table 1; Figure 1c). Although seed mass influenced the relationship between investments in dispersal structures, the positive allometry between fruit coat mass and elaiosome mass persisted regardless of seed mass (slope $=1.66$, $95 \% \mathrm{Cl}=1.28-2.17$, correlation $p=0.03$; Figure $1 d$ ). When incorporating phylogeny, there was a strong phylogenetic signal in all the models (see $\lambda$-values in Table 1), but the pRMA regressions gave qualitatively similar results with the cross-species analyses. In the context of phylogeny, fruit coat mass still scaled against seed mass positively, but at a lower rate than did elaiosome mass against seed mass (1.29 vs. 1.55; Table 1). Also, there remained a scaling relationship between fruit coat mass and elaiosome mass (pRMA slope $=1.18,95 \% \mathrm{Cl}=0.92-1.43$; Table 1), although the slope was not significantly different from 1 (i.e. isometry, $t_{(40.26)}=1.52, p=0.14$ to slope $=1$ ).

Fruit coats and seeds were significantly heavier in diplochorous Euphorbia species than in their ballistic relatives (Aim 2; mean $5.10 \mathrm{mg}$ vs. $1.38 \mathrm{mg}, \mathrm{t}_{(26.60)}=-3.21, p=0.003$ for fruit coat; mean $3.24 \mathrm{mg}$ vs. $1.15 \mathrm{mg}, t_{(24.96)}=-2.93, p=0.007$ for seed; Figure 2). However, after accounting for the evolutionary correlations among species, neither fruit coat mass nor seed mass was different between diplochorous Euphorbia species and their monochorous relatives $\left(F_{(1)}=14.11, p=0.40\right.$ for fruit coat; $F_{(1)}=13.72, p=0.41$ for seed). The difference between cross-species analysis and 
TAB LE 1 Summary of the parameters for the allometric relationships between masses of diaspore components in the diplochorous Euphorbia species. $\mathrm{N}$ stands for sample size (i.e. number of species in the model). Correlation $p$-value is from correlation test between two variables. Isometry $p$-value tests if the slope is equal to 1 . RMA, reduced major axis regression (also known as standard major axis regression); pRMA, phylogenetic reduced major axis regression

\begin{tabular}{|c|c|c|c|c|}
\hline & $\begin{array}{l}\text { Fruit coat mass - Seed } \\
\text { mass }\end{array}$ & $\begin{array}{l}\text { Elaiosome mass - Seed } \\
\text { mass }\end{array}$ & $\begin{array}{l}\text { Elaiosome mass - Fruit } \\
\text { coat mass }\end{array}$ & $\begin{array}{l}\text { Residuals of elaiosome } \\
\text { mass on seed mass - } \\
\text { Residuals of fruit coat } \\
\text { mass on seed mass }\end{array}$ \\
\hline Correlation $p$-value & $<0.001$ & $<0.001$ & $<0.001$ & 0.03 \\
\hline \multicolumn{5}{|l|}{ RMA } \\
\hline$N$ & 64 & 53 & 53 & 53 \\
\hline$R^{2}$ & 0.74 & 0.47 & 0.41 & 0.09 \\
\hline \multicolumn{5}{|l|}{ pRMA } \\
\hline$N$ & 60 & 49 & 49 & 49 \\
\hline Slope $(95 \% \mathrm{Cl})$ & $1.29(1.14-1.44)$ & $1.55(1.21-1.89)$ & $1.18(0.92-1.43)$ & $1.95(1.49-2.40)$ \\
\hline
\end{tabular}

phylogenetic analysis may stem from the fact that most diplochorous Euphorbia species we studied are in the subgenus Esula (Figure S1).

Across diplochorous species, neither mean seed dispersal distance $\left(t_{(25)}=-0.64, p=0.53\right)$ nor maximum seed dispersal distance $\left(t_{(19)}=1.46, p=0.16\right)$ was correlated between the ballochorous phase and the myrmecochorous phase (Aim 3; Figure 3). We further tested the correlations between the residuals of ballochory distance on seed mass and the residuals of myrmecochory distance on seed mass, but these relationships remained to be non-significant when taking seed mass into account $\left(t_{(25)}=0.31, p=0.76\right.$ for mean dispersal distance; $t_{(19)}=0.65, p=0.52$ for maximum dispersal distance). That is, we found no evidence that diplochorous species dispersing their seeds long distances in one phase have short dispersal distances in the other phase (i.e. a negative relationship/trade-off). We also found no evidence that diplochorous species that disperse their seeds greater distances in one phase also consistently do so in the other phase (i.e. a positive relationship).

For all ballochory, mean seed dispersal distance ranged from 0.072 to $23.45 \mathrm{~m}$, and maximum seed dispersal distance ranged from 0.4 to $100 \mathrm{~m}$ (Table S3). For all myrmecochory, mean seed dispersal distance ranged from 0.03 to $93.9 \mathrm{~m}$, and maximum seed dispersal distance ranged from 0.15 to $180 \mathrm{~m}$ (Table S3). We found no indication that mean or maximum dispersal distances in each diplochorous phase were shorter than those achieved by each respective monochory (Aim 4). The median values of seed dispersal distance in either the ballochorous phase or the myrmecochorous phase by diplochorous species were similar with the median values of sole ballochory distances or sole myrmecochory distances, respectively (all $\mathrm{M}-\mathrm{W}$ test $p \geq 0.32$ ). Consistently, $\mathrm{K}-\mathrm{S}$ tests also indicated that the distributions of seed dispersal distance were similar between groups (all
$\mathrm{K}-\mathrm{S}$ test $p \geq 0.20$; Figure 4$)$. That is, dispersal distance in each phase of diplochory is comparable to that in single dispersal syndromes.

\section{4 | DISCUSSION}

Our study is the first quantification of the relative importance of abiotic and biotic phases in diplochory across a geographically and taxonomically broad scale. The findings do not support a trade-off effect in dispersal investment or dispersal distance between the two phases of ballistic-ant diplochory, but suggest that the two phases form a coordinated dispersal strategy. Dispersal investments in the two phases covary across species differing in seed mass and show a strong phylogenetic signal in the Euphorbia species. Large seeds are more likely to evolve strong fruit coats to promote ballochory and present large elaiosomes to facilitate myrmecochory, resulting in additive benefits in both phases.

\section{1 | Advantages of two-phase seed dispersal}

Our results on seed dispersal distance (Figure 3 and Figure 4) indicate that diplochory provides seeds with potentially synergetic advantages. The presence of dispersal structures in both phases does not diminish the dispersal outcomes of either the ballochorous phase or the myrmecochorous phase (Figure 4). This finding overturns the previous assumption that species with sole myrmecochory disperse their seeds further than do diplochorous species in the myrmecochorous phase (Takahashi \& Itino, 2012). It also challenges the assumption that the presence of an elaiosome in diplochory weakens seed aerodynamics and reduces explosive dispersal distance (Narbona et al., 2016; Stamp \& Lucas, 1983). In this way, plant species adopting 

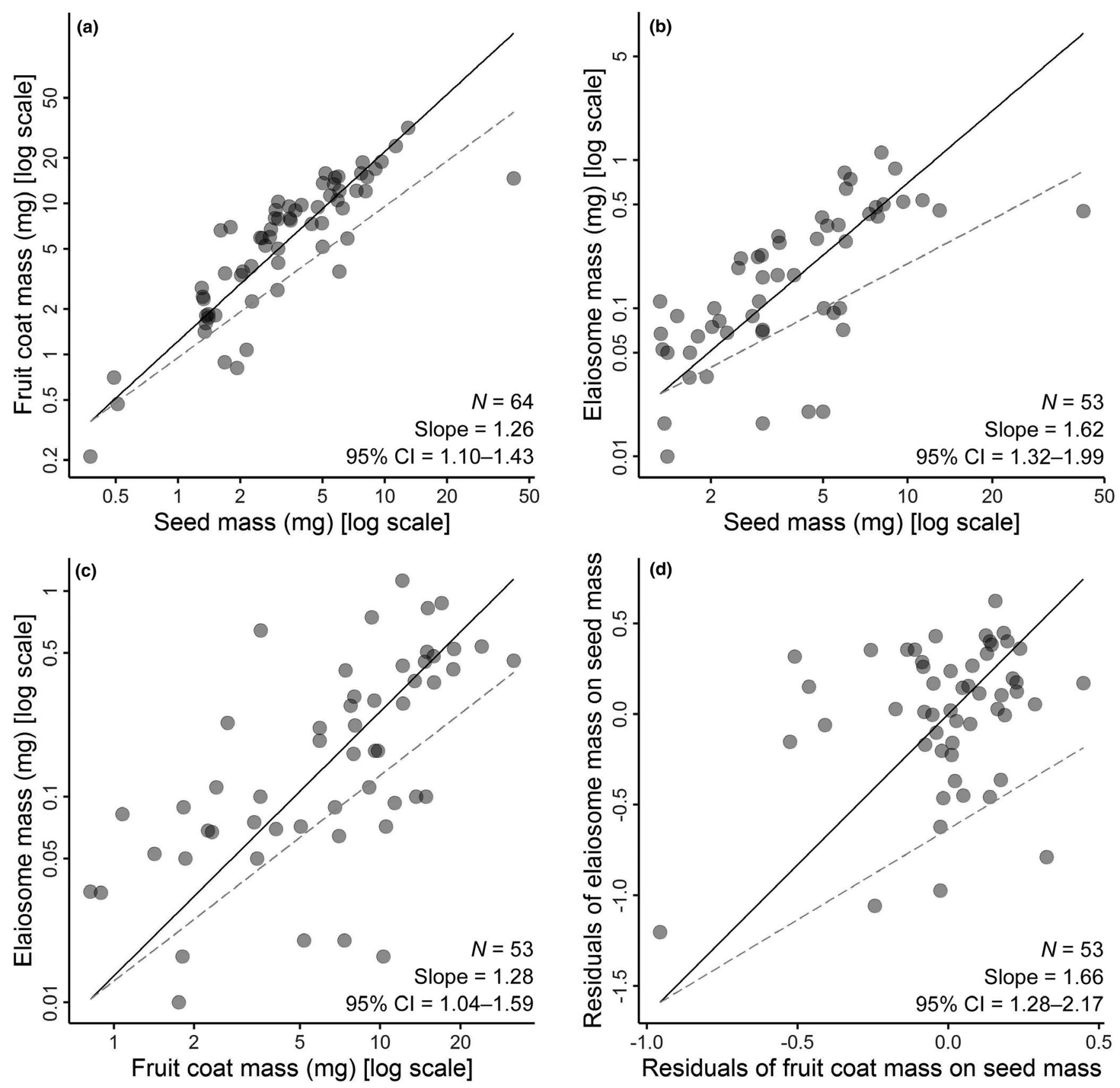

FIGURE 1 Allometry between masses of diaspore structures across diplochorous species in the Euphorbiaceae (Euphorbia species and Mercurialis annua). Solid lines are the reduced major axis slopes, and grey dashed lines show scaling slopes equalling to 1 (i.e. isometry). $\mathrm{N}$ stands for sample size; each dot stands for a species

two-phase dispersal are capable of achieving greater seed dispersal distance than those using sole ballochory or sole myrmecochory. The contribution of the two phases to effective dispersal may be simply additive (Beaumont, Mackay, \& Whalen, 2009), or have complementary and potentially even synergistic effects. While ballochory mainly contributes to distance dispersal, myrmecochory may contribute to a fine-tuning directed dispersal (Vander Wall \& Longland, 2004). Furthermore, the timing and scattering of seeds by ballochory may increase their chances of being dispersed disproportionally by highquality dispersers (Ohkawara \& Higashi, 1994; Aranda-Rickert \& Fracchia, 2010; see also discussion in Giladi, 2006). As suggested that short-distance dispersers may use small, widely spaced patches near parental plants (Stamp \& Lucas, 1983), diplochorous species could be likely to overcome habitat barriers. A survey of species spatial distribution across diplochorous species and their monochorous relatives could be a promising next step to test this idea.

The non-correlated seed dispersal distances (Figure 3) suggest that the two phases in diplochory can be independent of each other. This pattern results in species having a broad range of dispersal abilities in each phase and overall, from super dispersers to poor dispersers and everything in between (Figure 3 and Figure 4). The independence of the two phases provides seeds with additive 


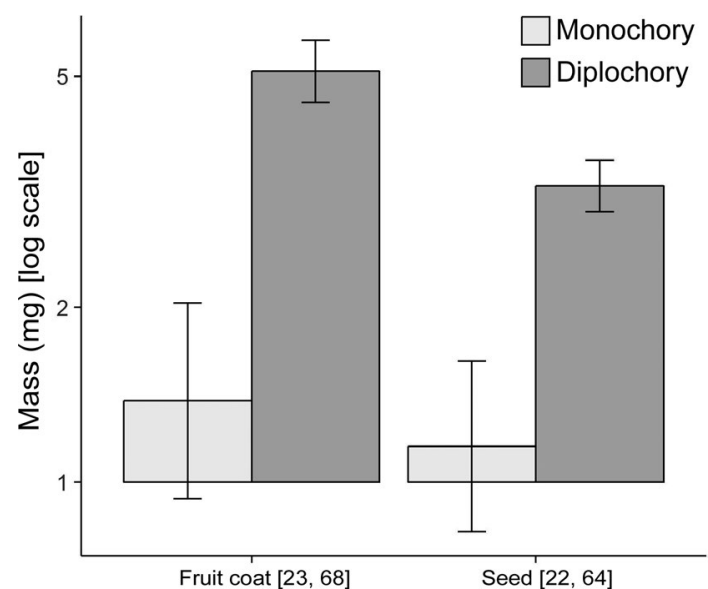

FIGURE 2 Comparisons of fruit coat mass and seed mass between monochorous (i.e. solely ballochorous) and diplochorous Euphorbia species. Bars represent standard errors. A comparison on elaiosome mass is not available, because Euphorbia species bearing elaiosomes are all diplochorous. Numbers in brackets stand for the numbers of species in each group

benefits. That is, diplochorous species acquire advantages in both ballochory and myrmecochory. Our cross-species finding is consistent with previous studies showing that ants dispersed seeds much further than explosive ejection in diplochorous species (Beaumont et al., 2009). Seed dispersal distance per se is a critical benefit of myrmecochory (Andersen, 1988; Giladi, 2006; Leal, Leal, \& Andersen, 2015), which for diplochorous plants may complement the low effectiveness of ballochory in dispersal distance. Beyond an additive dispersal distance, ballochory and myrmecochory together provide seeds with their respective benefits, including predation avoidance and directed dispersal. In addition to the dispersal function in ballochory, fruit coat can act as a barrier against pre-dispersal seed predation (Chen \& Moles, 2018), and explosive dehiscence can effectively leap away potential herbivores (Vaughn, Bowling, \& Ruel, 2011; Yano, 1997). Fruit coat intrinsically increases in size with its enclosed seed that is selected by various factors such as the tolerance to shade and desiccation. Greater investment in fruit coat could partially be the evolutionary response to the elevated risk of predispersal seed predation (but see Chen, Hemmings, Chen, \& Moles,
2017; Chen \& Moles, 2018). Since neither pre-dispersal seed predation nor defence is necessarily correlated with seed mass at the broad scale (Chen \& Moles, 2018; Moles, Warton, \& Westoby, 2003), the alternative role of fruit coat as the protective tissues requires a further investigation in species with ballochory. Nevertheless, the scattered pattern of seed distribution resulting from ballochory also reduces subsequent seed predation and increases the probability of seed removal by ants, especially by ant guilds that provide more effective dispersal (Bülow-Olsen, 1984; Giladi, 2006; Manzaneda \& Rey, 2008; and references herein). Sites where seeds are deposited by ants usually provide protection against above-ground predation while favouring seed survival, germination and seedling establishment (Beattie \& Lyons, 1975; Giladi, 2006; Hilley \& Thiet, 2015; Leal, Wirth, \& Tabarelli, 2007). The literature suggests that the two phases of diplochory could provide complementary benefits and increase seed dispersal effectiveness (Camargo et al., 2016; Culot et al., 2015; Schupp et al., 2010), and our results obviously shed new light on the spectrum of this scope.

\subsection{Allometry between diaspore structures}

Strong allometries between diaspore structures were found in this study, as well as a significant phylogenetic signal therein. Allometric scaling is a ubiquitous feature of biological systems, but the quantifications of such allometries rarely focus on dispersal structures. The size of fruit coat plays a positive and decisive role in the explosive power and subsequent dispersal distance (Hayashi, Gerry, \& Ellerby, 2010; Schmitt, Ehrhardt, \& Swartz, 1985). However, previous studies on diplochory have mainly focused on seed rather than fruit characteristics (but see Aranda-Rickert \& Fracchia, 2010). To our knowledge, our study is the first quantification of the reproductive allocations between two types of dispersal structures. In the mass scaling between fruit coat and elaiosome (Figure 1c), we suggest that the two diplochorous phases are coordinated in the Euphorbia species, where greater biomass is allocated to the myrmecochorous structures rather than to the ballochorous structures as the diaspore grows larger. The mass-mass allometry between the two dispersal structures persists no matter how seed mass changes (Figure 1d), both before and after accounting for the phylogenetic relationships
FIGURE 3 Correlations of mean seed dispersal distances (a) and maximum seed dispersal distances $(b)$ between ballochory and myrmecochory of diplochorous species. $\mathrm{N}$ stands for sample size; each dot stands for a species. $P$-values are non-significant in correlation tests. For visualization purposes, we set dot size as the logarithm of the species' seed mass

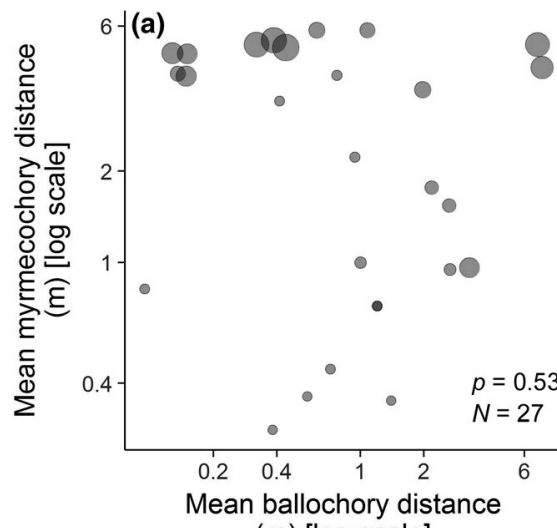

(m) [log scale]

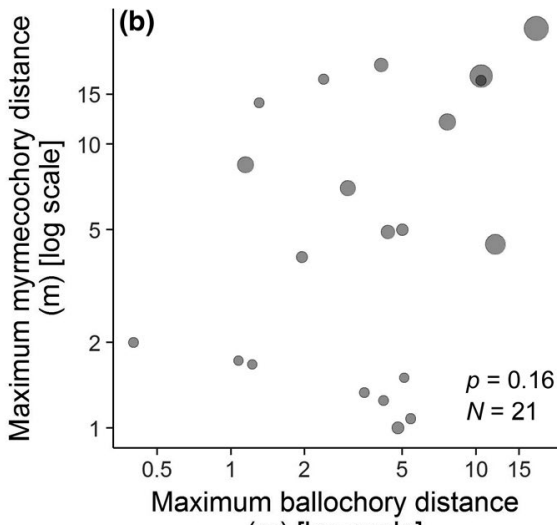

(m) [log scale] 

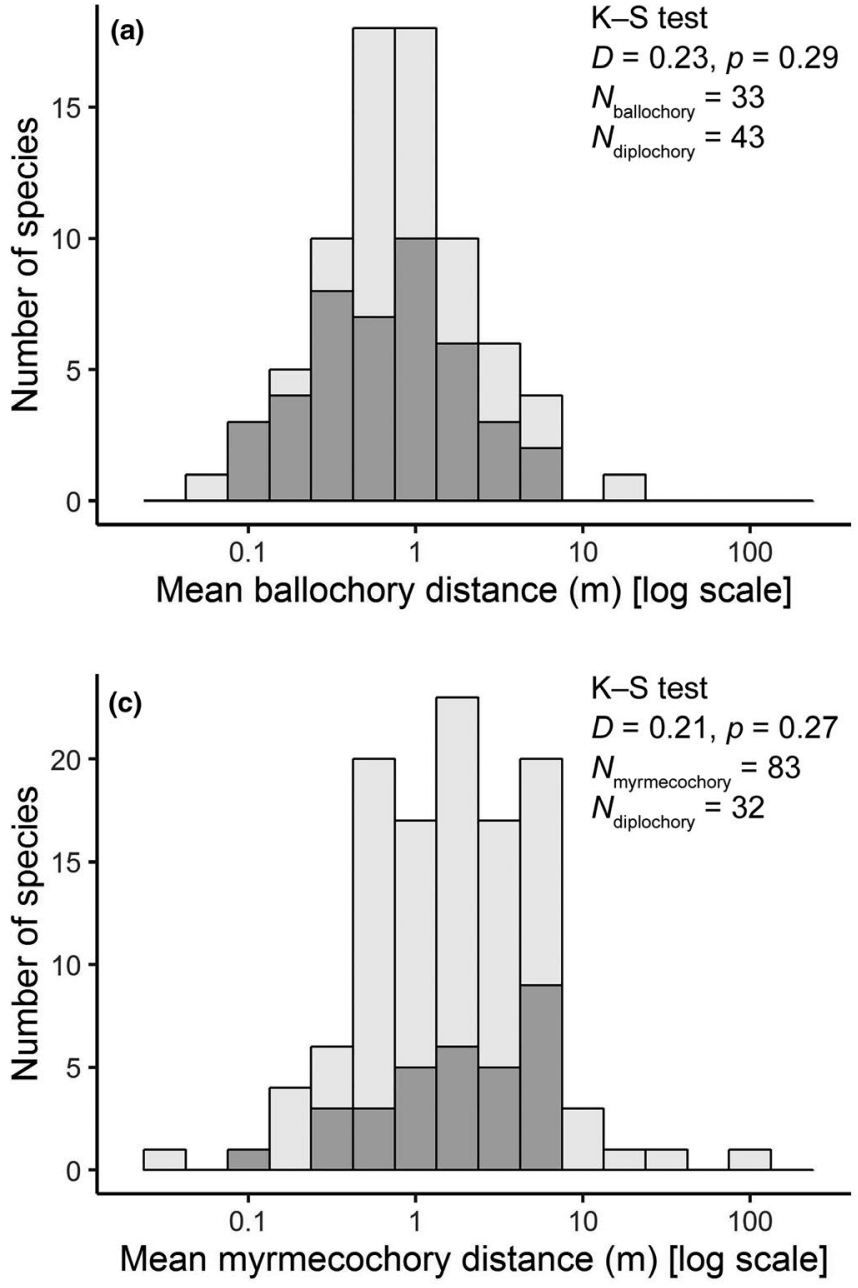
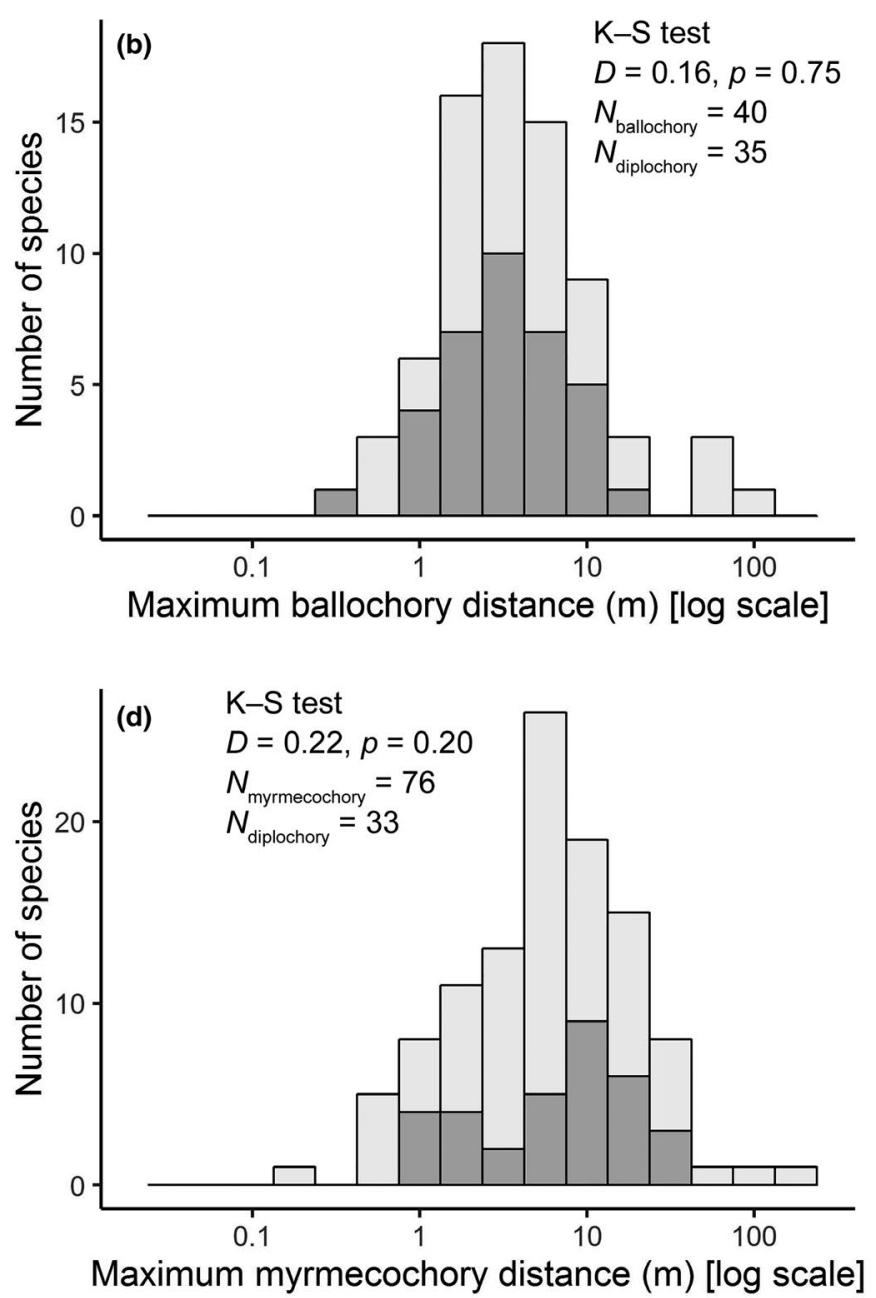

FIGURE 4 Distributions of mean and maximum seed dispersal distance in ballochory (a, b), myrmecochory (c, d). The bars correspond to a stacked column representation. Records with ballistic-ant diplochory are coloured in dark grey, otherwise in light grey. $\mathrm{N}$ stands for sample size. The Kolmogorov-Smirnov tests (K-S test) suggest that the dispersal distance distributions between the ballochorous phase of diplochory and sole ballochory, or between the myrmecochorous phase of diplochory and sole myrmecochory, are non-significantly different

among species. Although, in general, dispersal investment positively affects seed dispersal distance (Thomson et al., 2018), the efficiency of biomass investments in dispersal structures may vary across dispersal syndromes. The efficiency of energy transfer from fruit coat to seed is hypothesized to be generally low or highly variable (Hayashi et al., 2009). Thus, our finding of a positive allometry may be due to the low efficiency and effectiveness of ballochory, and the relatively high benefits gained from myrmecochory (Hayashi et al., 2009), so that relative biomass allocations tend to the myrmecochorous phase in diplochory.

Dispersal investments in both diplochorous phases positively scaled with seed mass (Figure 1a,b). This result again reflects a higher reliance on the myrmecochorous phase, as the allometric power between seed mass and elaiosome mass is greater than that between seed mass and fruit coat mass. Within Acacia species and a few other species, Edwards et al. (2006) have found a positive allometry between elaiosome mass and seed mass, but a much lower scaling slope $(1.24$ with $95 \% \mathrm{Cl}=1.17-1.32)$ than ours (Table 1 ;
Figure 1b). A few studies on other forms of dispersal investment (e.g. pulp, pericarp) have also found lower scaling slopes between dispersal structures and seed compared to our result (Chen, Felker, \& Sun, 2010; Edwards, 2006). The high value of scaling slope between elaiosome mass and seed mass in our study suggests that natural selection on the myrmecochory of Euphorbia species is likely to be strong.

\section{3 | Dispersal difficulty for large seeds}

The strategy to develop double dispersal structures can be costly in terms of both energy and materials, but provides large seeds with additive advantages to outweigh the costs. Although it has been generally assumed that large seeds usually face dispersal difficulties (synthesized in Thomson, Moles, Auld, \& Kingsford, 2011), the effects of seed mass and especially of elaiosome/seed mass ratio on seed removal rate and on seed fate are not always simple, at least in the case of myrmecochory. Beyond a certain mass, seeds can be too 
large to be carried by ants (Leal et al., 2007). Within the narrow range of seed mass in myrmecochores (Moles et al., 2005), seed mass is likely to increase seed removal by high-quality dispersers (Leal, Neto, Oliveira, Andersen, \& Leal, 2014), but has no effect on poor-quality dispersers (Warren \& Giladi, 2014). In the current study, we show in diplochory that large-seeded species tend to disperse seeds even further than do small-seeded species (Figure 3). The greater rate of mass scaling in dispersal structures than that in seed (i.e. RMA slope larger than 1; Figure 1a,b) shows that a larger seed invests proportionally more biomass in dispersal structures, which may help to overcome potential difficulties in dispersal. The additive benefits of diplochory could be a reason for the increased probability of displaying diplochory in large-seeded Euphorbia species (Figure 2), such as the species of the subgenus Esula (Figure S1; Pahlevani \& Akhani, 2011; Pahlevani, Liede-Schumann, \& Akhani, 2015). In diplochory, a thickened fruit coat increases the probability of reliable launching (Hayashi et al., 2009), and a conspicuous elaiosome assures high efficiency and effectiveness of diaspore removal by ants (Mark \& Olesen, 1996). Compared to small-seeded species, large-seeded species are more likely to allocate extra energy and materials to construct both structures of thickened fruit coats and conspicuous elaiosomes. The approach we used with Euphorbia could be adopted to study other large clades where species evolve diplochory and show relatively high variations in seed mass and dispersal structure mass (e.g. Croton, Jatropha; Riina, Ee, Wiedenhoeft, Cardozo, \& Berry, 2010; Murthy, Chamundeswari, Goverdhen, \& Bahadur, 2013).

In conclusion, our findings do not support the idea of trade-offs between the two phases of diplochory. Rather, ballochory and myrmecochory are combined as a coordinated dispersal strategy in diplochory, where investment in one dispersal syndrome does not impair the performance of the other. The double dispersal syndromes bring combined benefits to seed dispersal, especially to large-seeded species. These results advance our understanding of plant reproductive strategies, by examining the relative importance of dispersal investments and dispersal distances in two-phase seed dispersal.

\section{ACKNOWLEDGEMENTS}

We thank Gilad Ben-Zvi and Nataly Levine for providing experimental materials; Xiao-Fan Wang, Gao Chen and Zhi-Gao Du for their assistance in measuring herbarium samples; Ya-Huang Luo and John Dickie for beneficial discussion. We also thank the editor and two anonymous reviewers for valuable comments on an earlier draft of this paper. S.-C.C is supported by a postdoctoral fellowship from the Blaustein Center for Scientific Cooperation, and an Israel Science Foundation grant to I.G. (No. 834/15). R.R. is supported by grant CGL2015-73621-JIN (AEI/FEDER). This is publication \#1020 of the Mitrani Department of Desert Ecology.

\section{AUTHORS' CONTRIBUTIONS}

S.-C.C. and F.J.T. conceived the idea and designed the study; S.-C.C., A.H.P. and L.M. collected the data; S.-C.C. and R.R. analysed the data; and S.-C.C. led the manuscript writing, with major contributions from F.J.T. and I.G.

\section{DATA ACCESSIBILITY}

All data used in the manuscript are available from the Dryad Digital Repository: https://doi.org/10.5061/dryad.076g250 (Chen et al., 2019a).

\section{ORCID}

Si-Chong Chen (iD https://orcid.org/0000-0002-6855-2595

Itamar Giladi iD https://orcid.org/0000-0003-0240-7480

\section{REFERENCES}

Andersen, A. N. (1988). Dispersal distance as a benefit of myrmecochory. Oecologia, 75, 507-511. https://doi.org/10.1007/BF00776412

Aranda-Rickert, A., \& Fracchia, S. (2010). Diplochory in two Jatropha (Euphorbiaceae) species of the Monte Desert of Argentina. Austral Ecology, 35, 226-235. https://doi. org/10.1111/j.1442-9993.2009.02030.x

Baiges, J. C., Espadaler, X., \& Blanché, C. (1991). Seed dispersal in W Mediterranean Euphorbia species. Botanika Chronika, 10, 697-705.

Beattie, A. J., \& Lyons, N. (1975). Seed dispersal in Viola (Violaceae): Adaptations and strategies. American Journal of Botany, 62, 714-722. https://doi.org/10.1002/j.1537-2197.1975.tb14104.x

Beaumont, K. P., Mackay, D. A., \& Whalen, M. A. (2009). Combining distances of ballistic and myrmecochorous seed dispersal in Adriana quadripartita (Euphorbiaceae). Acta Oecologica, 35, 429-436. https:// doi.org/10.1016/j.actao.2009.01.005

Berg, R. Y. (1966). Seed dispersal of Dendromecon: Its ecologic, evolutionary, and taxonomic significance. American Journal of Botany, 53, 61-73. https://doi.org/10.1002/j.1537-2197.1966.tb07298.x

Bülow-Olsen, A. (1984). Diplochory in Viola: A possible relation between seed dispersal and soil seed bank. American Midland Naturalist, 112, 251-260. https://doi.org/10.2307/2425432

Camargo, P. H. S. A., Martins, M. M., Feitosa, R. M., \& Christianini, A. V. (2016). Bird and ant synergy increases the seed dispersal effectiveness of an ornithochoric shrub. Oecologia, 181, 507-518. https://doi. org/10.1007/s00442-016-3571-z

Chen, H., Felker, S., \& Sun, S. (2010). Allometry of within-fruit reproductive allocation in subtropical dicot woody species. American Journal of Botany, 97, 611-619. https://doi.org/10.3732/ajb.0900204

Chen, S.-C., \& Giladi, I. (2018). Allometric relationships between masses of seed functional components. Perspectives in Plant Ecology, Evolution and Systematics, 35, 1-7. https://doi.org/10.1016/j. ppees.2018.09.005

Chen, S.-C., Hemmings, F. A., Chen, F., \& Moles, A. T. (2017). Plants do not suffer greater losses to seed predation towards the tropics. Global Ecology and Biogeography, 26, 1283-1291. https://doi.org/10.1111/ geb.12636

Chen, S.-C., \& Moles, A. T. (2018). Factors shaping large-scale gradients in seed physical defence: Seeds are not better defended towards the tropics. Global Ecology and Biogeography, 27, 417-428. https://doi. org/10.1111/geb.12704

Chen, S., Pahlevani, A. H., Malíková, L., Riina, R., Thomson, F. J., \& Giladi, I. (2019a). Data from: Trade-off or coordination? Correlations between ballochorous and myrmecochorous phases of diplochory. Dryad Digital Repository. https://doi.org/10.5061/ dryad.076g250. 
Chen, S.-C., Tamme, R., Thomson, F. J., \& Moles, A. T. (2019b). Seeds tend to disperse further in the tropics. Ecology Letters, 22, 954-961. https:// doi.org/10.1111/ele.13255

Christianini, A. V., \& Oliveira, P. S. (2010). Birds and ants provide complementary seed dispersal in a neotropical savanna. Journal of Ecology, 98, 573-582. https://doi.org/10.1111/j.1365-2745.2010.01653.x

R Core Team (2014) R: a language and environment for statistical computing. Vienna, Austria: R Foundation for Statistical Computing.

Culot, L., Huynen, M.-C., \& Heymann, E. W. (2015). Partitioning the relative contribution of one-phase and two-phase seed dispersal when evaluating seed dispersal effectiveness. Methods in Ecology and Evolution, 6, 178-186. https://doi.org/10.1111/2041-210X. 12317

Culver, D. C., \& Beattie, A. J. (1978). Myrmecochory in Viola: Dynamics of seed-ant interactions in some West Virginia species. Journal of Ecology, 66, 53-72. https://doi.org/10.2307/2259181

Edwards, W. (2006). Plants reward seed dispersers in proportion to their effort: The relationship between pulp mass and seed mass in vertebrate dispersed plants. Evolutionary Ecology, 20, 365-376. https:// doi.org/10.1007/s10682-006-0006-z

Edwards, W., Dunlop, M., \& Rodgerson, L. (2006). The evolution of rewards: Seed dispersal, seed size and elaiosome size. Journal of Ecology, 94, 687-694. https://doi.org/10.1111/j.1365-2745.2006.01116.x

Ensslin, A., \& Godefroid, S. (2019). How the cultivation of wild plants in botanic gardens can change their genetic and phenotypic status and what this means for their conservation value. Sibbaldia: The Journal of Botanic Garden. Horticulture, 17, 51-70.

Giladi, I. (2006). Choosing benefits or partners: A review of the evidence for the evolution of myrmecochory. Oikos, 112, 481-492. https://doi. org/10.1111/j.0030-1299.2006.14258.x

Hayashi, M., Feilich, K. L., \& Ellerby, D. J. (2009). The mechanics of explosive seed dispersal in orange jewelweed (Impatiens capensis). Journal of Experimental Botany, 60, 2045-2053. https://doi.org/10.1093/jxb/ erp070

Hayashi, M., Gerry, S. P., \& Ellerby, D. J. (2010). The seed dispersal catapult of Cardamine parviflora (Brassicaceae) is efficient but unreliable. American Journal of Botany, 97, 1595-1601. https://doi.org/10.3732/ ajb.1000173

Hilley, E., \& Thiet, R. (2015). Vulnerable broom crowberry (Corema conradii) benefits from ant seed dispersal in coastal US heathlands. Plant Ecology, 216, 1091-1101. https://doi.org/10.1007/ s11258-015-0493-5

Howe, H. F., \& Smallwood, J. (1982). Ecology of seed dispersal. Annual Review of Ecology and Systematics, 13, 201-228. https://doi. org/10.1146/annurev.es.13.110182.001221

Hughes, L., \& Westoby, M. (1992). Effect of diaspore characteristics on removal of seeds adapted for dispersal by ants. Ecology, 73, 13001312. https://doi.org/10.2307/1940677

Leal, I. R., Leal, L. C., \& Andersen, A. N. (2015). The benefits of myrmecochory: A matter of stature. Biotropica, 47, 281-285. https://doi. org/10.1111/btp.12213

Leal, I. R., Wirth, R., \& Tabarelli, M. (2007). Seed dispersal by ants in the semi-arid Caatinga of north-east Brazil. Annals of Botany, 99, 885894. https://doi.org/10.1093/aob/mcm017

Leal, L. C., Neto, M. C. L., de Oliveira, A. F. M., Andersen, A. N., \& Leal, I. R. (2014). Myrmecochores can target high-quality disperser ants: Variation in elaiosome traits and ant preferences for myrmecochorous Euphorbiaceae in Brazilian Caatinga. Oecologia, 174, 493-500. https://doi.org/10.1007/s00442-013-2789-2

Lima, M. H., Oliveira, E. G., \& Silveira, F. A. (2013). Interactions between ants and non-myrmecochorous fruits in Miconia (Melastomataceae) in a neotropical savanna. Biotropica, 45, 217-223. https://doi. org/10.1111/j.1744-7429.2012.00910.x

Lisci, M., \& Pacini, E. (1997). Fruit and seed structural characteristics and seed dispersal in Mercurialis annua L. (Euphorbiaceae). Acta Societatis
Botanicorum Poloniae, 66, 379-386. https://doi.org/10.5586/ asbp.1997.047

Manzaneda, A. J., \& Rey, P. J. (2008). Geographic variation in seed removal of a myrmecochorous herb: Influence of variation in functional guild and species composition of the disperser assemblage through spatial and temporal scales. Ecography, 31, 583-591. https://doi. org/10.1111/j.0906-7590.2008.05345.x

Mark, S., \& Olesen, J. M. (1996). Importance of elaiosome size to removal of ant-dispersed seeds. Oecologia, 107, 95-101. https://doi. org/10.1007/BF00582239

Moles, A. T., Ackerly, D. D., Webb, C. O., Tweddle, J. C., Dickie, J. B., Pitman, A. J., \& Westoby, M. (2005). Factors that shape seed mass evolution. Proceedings of the National Academy of Sciences of the United States of America, 102, 10540-10544. https://doi. org/10.1073/pnas.0501473102

Moles, A. T., Warton, D. I., \& Westoby, M. (2003). Do small-seeded species have higher survival through seed predation than large-seeded species? Ecology, 84, 3148-3161. https://doi.org/10.1890/02-0662

Murthy, G. V. S., Chamundeswari, E., Goverdhen, S., \& Bahadur, B. (2013). In B. Bahadur, M. Sujatha, \& N. Carels (Eds.), Fruit, seed and seedling characters in Jatropha L. Jatropha, challenges for a new energy crop (pp. 95-118). New York, NY: Springer. https://doi. org/10.1007/978-1-4614-4915-7_7

Nakanishi, H. (1994). Myrmecochorous adaptations of Corydalis species (Papaveraceae) in southern Japan. Ecological Research, 9, 1-8. https:// doi.org/10.1007/BF02347236

Narbona, E., Arista, M., \& Ortiz, P. L. (2005). Explosive seed dispersal in two perennial Mediterranean Euphorbia species (Euphorbiaceae). American Journal of Botany, 92, 510-516. https://doi.org/10.3732/ ajb.92.3.510

Narbona, E., Ortiz, P., \& Arista, M. (2016). The possible advantage of myrmecochory in diplochorous species: A test on two Mediterranean Euphorbia species. Plant Biosystems, 150, 111-120. https://doi. org/10.1080/11263504.2014.983205

Ohkawara, K., \& Higashi, S. (1994). Relative importance of ballistic and ant dispersal in two diplochorous Viola species (Violaceae). Oecologia, 100, 135-140. https://doi.org/10.1007/BF00317140

Pahlevani, A. H., \& Akhani, H. (2011). Seed morphology of Iranian annual species of Euphorbia (Euphorbiaceae). Botanical Journal of the Linnean Society, 167, 212-234. https://doi. org/10.1111/j.1095-8339.2011.01165.x

Pahlevani, A. H., Liede-Schumann, S., \& Akhani, H. (2015). Seed and capsule morphology of Iranian perennial species of Euphorbia (Euphorbiaceae) and its phylogenetic application. Botanical Journal of the Linnean Society, 177, 335-377. https://doi.org/10.1111/boj.12245

Paradis, E., Claude, J., \& Strimmer, K. (2004). APE: Analyses of phylogenetics and evolution in R language. Bioinformatics, 20, 289-290. https ://doi.org/10.1093/bioinformatics/btg412

Passos, L., \& Oliveira, P. S. (2002). Ants affect the distribution and performance of seedlings of Clusia criuva, a primarily bird-dispersed rain forest tree. Journal of Ecology, 90, 517-528. https://doi. org/10.1046/j.1365-2745.2002.00687.x

Revell, L. J. (2012). Phytools: An R package for phylogenetic comparative biology (and other things). Methods in Ecology and Evolution, 3, 217-223. https://doi.org/10.1111/j.2041-210X.2011.00169.x

Riina, R., Peirson, J. A., Geltman, D. V., Molero, J., Frajman, B., Pahlevani, A. H., ... Berry, P. E. (2013). A worldwide molecular phylogeny and classification of the leafy spurges, Euphorbia subgenus Esula (Euphorbiaceae). Taxon, 62, 316-342. https://doi.org/10.12705/ 622.1

Riina, R., van Ee, B., Wiedenhoeft, A. C., Cardozo, A., \& Berry, P. E. (2010). Sectional rearrangement of arborescent clades of Croton (Euphorbiaceae) in South America: Evolution of arillate seeds and a new species, Croton domatifer. Taxon, 59, 1147-1160. https://doi. org/10.1002/tax.594014 
Schmitt, J., Ehrhardt, D., \& Swartz, D. (1985). Differential dispersal of self-fertilized and outcrossed progeny in jewelweed (Impatiens capensis). American Naturalist, 126, 570-575. https://doi.org/10.1086/ 284439

Schupp, E. W., Jordano, P., \& Gómez, J. M. (2010). Seed dispersal effectiveness revisited: A conceptual review. New Phytologist, 188, 333353. https://doi.org/10.1111/j.1469-8137.2010.03402.x

Stamp, N. E., \& Lucas, J. R. (1983). Ecological correlates of explosive seed dispersal. Oecologia, 59, 272-278. https://doi.org/10.1007/BF003 78848

Takahashi, S., \& Itino, T. (2012). Larger seeds are dispersed farther: The long-distance seed disperser ant Aphaenogaster famelica prefers larger seeds. Sociobiology, 59, 1401-1411. https://doi.org/10.13102/ sociobiology.v59i4.888

Thomson, F. J., Letten, A. D., Tamme, R., Edwards, W., \& Moles, A. T. (2018). Can dispersal investment explain why tall plant species achieve longer dispersal distances than short plant species? New Phytologist, 217, 407-415. https://doi.org/10.1111/nph.14735

Thomson, F. J., Moles, A. T., Auld, T. D., \& Kingsford, R. T. (2011). Seed dispersal distance is more strongly correlated with plant height than with seed mass. Journal of Ecology, 99, 1299-1307. https://doi. org/10.1111/j.1365-2745.2011.01867.x

Vander Wall, S. B., \& Longland, W. S. (2004). Diplochory: Are two seed dispersers better than one? Trends in Ecology \& Evolution, 19, 155161. https://doi.org/10.1016/j.tree.2003.12.004

Vaughn, K. C., Bowling, A. J., \& Ruel, K. J. (2011). The mechanism for explosive seed dispersal in Cardamine hirsuta (Brassicaceae). American Journal of Botany, 98, 1276-1285. https://doi.org/10.3732/ ajb.1000374

Warren, R. J., \& Giladi, I. (2014). Ant-mediated seed dispersal: A few ant species (Hymenoptera: Formicidae) benefit many plants. Myrmecological News, 20, 129-140.
Warton, D. I., Duursma, R. A., Falster, D. S., \& Taskinen, S. (2012). Smatr 3 - an R package for estimation and inference about allometric lines. Methods in Ecology and Evolution, 3, 257-259. https://doi. org/10.1111/j.2041-210X.2011.00153.x

Wu, L.-M., Chen, S.-C., \& Wang, B. (2019). An allometry between seed kernel and seed coat shows greater investment in physical defense in small seeds. American Journal of Botany, 106, 371-376. https://doi. org/10.1002/ajb2.1252

Yano, S. (1997). Silique burst of Cardamine scutata (Cruciferae) as a physical inducible defense against seed predatory caterpillars. Researches on Population Ecology, 39, 95-100. https://doi.org/10.1007/BF027 65254

Zhu, Y., Wang, D., Zhang, L., \& Liu, M. (2018). Differential importance of consecutive dispersal phases in two ant-dispersed Corydalis species (Papaveraceae). Nordic Journal of Botany, 36, e01644. https://doi. $\operatorname{org} / 10.1111 /$ njb.01644

\section{SUPPORTING INFORMATION}

Additional supporting information may be found online in the Supporting Information section at the end of the article.

How to cite this article: Chen S-C, Pahlevani AH, Malíková L, Riina R, Thomson FJ, Giladi I. Trade-off or coordination? Correlations between ballochorous and myrmecochorous phases of diplochory. Funct Ecol. 2019;33:1469-1479. https:// doi.org/10.1111/1365-2435.13353 